\title{
Disentangling residents' engagement with communities of clinical practice in the workplace
}

Citation for published version (APA):

Olmos-Vega, F. M., Dolmans, D. H. J. M., Guzman-Quintero, C., Echeverri-Rodriguez, C., Teunnissen, P. W., \& Stalmeijer, R. E. (2019). Disentangling residents' engagement with communities of clinical practice in the workplace. Advances in Health Sciences Education, 24(3), 459-475. https://doi.org/10.1007/s10459019-09874-9

Document status and date:

Published: 01/08/2019

DOI:

10.1007/s10459-019-09874-9

Document Version:

Publisher's PDF, also known as Version of record

Document license:

Taverne

Please check the document version of this publication:

- A submitted manuscript is the version of the article upon submission and before peer-review. There can be important differences between the submitted version and the official published version of record.

People interested in the research are advised to contact the author for the final version of the publication, or visit the DOI to the publisher's website.

- The final author version and the galley proof are versions of the publication after peer review.

- The final published version features the final layout of the paper including the volume, issue and page numbers.

Link to publication

\footnotetext{
General rights Owners
rights.

- You may freely distribute the URL identifying the publication in the public portal. please follow below link for the End User Agreement:

www.umlib.nl/taverne-license

Take down policy

If you believe that this document breaches copyright please contact us at:

repository@maastrichtuniversity.nl

providing details and we will investigate your claim.
}

Copyright and moral rights for the publications made accessible in the public portal are retained by the authors and/or other copyright owners and it is a condition of accessing publications that users recognise and abide by the legal requirements associated with these

- Users may download and print one copy of any publication from the public portal for the purpose of private study or research.

- You may not further distribute the material or use it for any profit-making activity or commercial gain

If the publication is distributed under the terms of Article $25 \mathrm{fa}$ of the Dutch Copyright Act, indicated by the "Taverne" license above, 


\title{
Disentangling residents' engagement with communities of clinical practice in the workplace
}

\author{
Francisco M. Olmos-Vega ${ }^{1,2}$ (D) . Diana H. J. M. Dolmans ${ }^{3}$. Carlos Guzmán-Quintero ${ }^{4}$. \\ Camila Echeverri-Rodriguez ${ }^{1} \cdot$ Pim W. Teunnissen $^{3,5} \cdot$ Renée E. Stalmeijer $^{3}$
}

Received: 5 June 2018 / Accepted: 10 January 2019 / Published online: 18 January 2019

(c) Springer Nature B.V. 2019

\begin{abstract}
Maximising the potential of the workplace as a learning environment entails understanding the complexity of its members' interactions. Although some articles have explored how residents engage with supervisors, nurses and pharmacists individually, there is little research on how residents enter into and engage with the broader community of clinical practice (CoCP). To this end, we designed a constructivist grounded theory study that took place at Universidad Javeriana in Bogotá, Colombia. We conducted semi-structured interviews with 13 residents from different training levels and disciplines during the first weeks of their new rotations. During the interviews, we used the Pictor technique as a visual aid to collect data. Using iterative data collection and analysis, constant comparison methods and theoretical sampling, we constructed the final results. When entering a CoCP, residents experienced recurring and intertwined processes including: exploring how their goals and interest are aligned with those of the CoCP; identifying the relevant $\mathrm{CoCP}$ members in the workplace environment; and understanding how these members could assist their successful engagement with the community's practices. Residents entered a CoCP with the intention of either having a central or a peripheral trajectory in it. The final resident participation and role resulted from negotiations between the resident and the CoCP members. Optimising workplace learning includes being mindful as to how each member of the healthcare team influence residents' engagement on practice, and on understanding the nuances of residents' participatory trajectories while interacting with them. Understanding such nuances could be key to align CoCPs' learning affordances and residents' goals and intentions.
\end{abstract}

Keywords Communities of practice $\cdot$ Co-participation theory $\cdot$ Interprofessional collaboration $\cdot$ Postgraduate medical education $\cdot$ Workplace learning

Francisco M. Olmos-Vega

folmos@javeriana.edu.co; fmolmos@husi.org.co

Extended author information available on the last page of the article 


\section{Introduction}

Workplace learning is critical to the process of becoming a medical professional (Teunissen 2014). However, as learning environments, clinical workplaces are unstructured, which often results in residents missing learning opportunities that are afforded to them in the clinical setting (Billett 2002). Other professionals' lack of acceptance of residents as participants within the healthcare team constitutes one reason for this problem (Bannister et al. 2018; Goldman et al. 2015). Understanding how residents enter and engage with the members of communities of clinical practice $(\mathrm{CoCP})$ is therefore crucial to maximising workplace learning (Cruess et al. 2018; Egan and Jaye 2009; Swanwick 2005).

Optimising the workplace as a learning environment requires mapping the complexity of its members' interactions, a challenge that could be approached by understanding learning as a social endeavour (Billett 2002; Eraut 2004; Lave and Wenger 1991). Lave and Wenger, for example, asserted that learning is a social process that involves negotiating different forms of participation within communities of practice (Lave and Wenger 1991). These authors understand learner participation as active engagement with the practices of those communities (Wenger 1998), either as apprentices interested in an inbound trajectory towards full participation or as passing visitors who aim to remain on the periphery of the community (Fenton-O'Creevy et al. 2014). The participation of newcomers is legitimised when it is supported and approved by the existing and more experienced members of a community (Wenger 1998; Wenger-Trayner and Wenger-Trayner 2014), who could choose to either create or withhold learning opportunities for the newcomers (Bannister et al. 2018). Given that residents enter different CoCPs as part of their training, they continuously face the challenge to participate in and engage with various and dissimilar healthcare teams (Cruess et al. 2018; Egan and Jaye 2009; Swanwick 2005).

Entering and engaging with CoCPs entails collaborating with the diverse members of the healthcare team, including supervisors, peers, nurses and, for instance, administrative personnel. Much of the existing literature has focused on how residents learn in the workplace from their interactions with clinical supervisors (Brown et al. 2017; Olmos-Vega et al. 2018; Olmos-Vega et al. 2017; Ong et al. 2016; Teunissen et al. 2007a, b), with few studies delving into the role of other actors, including nurses (Burford et al. 2013; Varpio et al. 2014) and pharmacists (Noble et al. 2017). Moreover, there is no empirical literature on how residents engage with the broader CoCP. In an attempt to better understand interprofessional collaboration, a number of papers have studied how healthcare teams work together from a sociocultural approach, including studies conducted in operating rooms (Collin et al. 2010; Gillespie et al. 2013), intensive care units (ICUs) (Paradis et al. 2016), outpatient clinics (Lingard et al. 2017) and in a combination of these settings (Bunniss and Kelly 2013; Lingard et al. 2012). What transpires from this work is the fact that interprofessional healthcare teams constitute complex systems that continually negotiate their responses to day-to-day, contextually bound challenges while trying to address unstable membership and continuously changing roles. Although most of this literature includes residents as members of the team, the primary focus is on how members of the team collaborate with each other and not how residents enter such teams and engage with team members.

The purpose of our study is therefore to understand how residents enter CoCPs and engage with $\mathrm{CoCP}$ members, which includes how residents address the complexity of the interactions within such communities. To this end, we designed a constructivist grounded theory (CGT) study (Charmaz 2014) in which we interviewed residents from different 
disciplines and levels of training using a visual aid called the Pictor technique (King et al. 2013).

\section{Methods}

We chose CGT as our methodology because it allowed us to construct empirically grounded conceptualisations of the data, enabling us to make theoretical constructions using participants' experiences, researchers' beliefs and sensitising concepts drawn from socio-cultural theoretical frameworks (Charmaz 2014). By using CGT, we intend to not only describe residents' experiences but also unveil the social processes that lead to residents' workplace learning through their interactions with an interprofessional health care team (Watling and Lingard 2012). We followed the principal tenets of CGT, including iterative data collection and analysis, constant comparison techniques and theoretical sampling, to ensure the strength of our findings (Charmaz 2014; Watling and Lingard 2012).

\section{Research team}

The interdisciplinary research team included an anaesthesiologist pursuing a $\mathrm{PhD}$ in health professions education (FOV), two educationalists with expertise in learning environments (DD) and workplace learning (RS), an obstetrician and medical education researcher in the field of workplace learning (PT), an anthropologist pursuing a master's degree in bioethics (CGQ) and a 4th-year medical student (CER). We took advantage of this diversity by broadening the perspectives through which we analysed the data and constructed our results, including arriving at consensus and negotiating our disagreements (Varpio et al. 2017).

\section{Reflexivity}

Our research is informed by a social constructivist paradigm. Social constructivism states that learning is the result of students' social interactions within a specific context (Gergen 2009), a paradigm that is aligned with our research question. Regarding the influence of the research interest, we clarify that the first author is a clinical supervisor in the research setting and as such, held a power position with the participants of the study. To mitigate this influence, most of the invitations to participate in the study were extended by CGQ, who also conducted most of the interviews. When FOV conducted the interviews, they were held outside the hospital in more neutral contexts. CER was a 4th-year medical student during the data collection and analysis, which resulted in her being part of a $\mathrm{CoCP}$ at the same time as some of our participants. The rest of the team were outsiders to the study setting with no previous contact with the participants. FOV's and CER's memo-writing allowed them to explore and clarify their influence on the data, highlighting preconceptions about how residents interact with other actors in the workplace. Such preconceptions were presented with transparency to the rest of the team to be contested by them. Having a mixed team of insiders/outsiders increased the quality of data collection and analysis, for example, we noticed how interviews performed by CGQ (an outsider) differed from those conducted by FOV (an insider). We observed how residents tried to be more detailed on their answers and how they used more jargon-free language when explaining their experiences to an outsider, who, in turn, asked for more details in their descriptions which would 
have been taken for granted by an insider. This analysis pushed FOV to create some distance from the participants to obtain richer data for a single interview, for example, by asking them to explain specific expressions and to elaborate on their reactions while proving them through their explanations.

\section{Setting}

This study took place in Bogotá, Colombia. The participants were residents at Pontificia Universidad Javeriana rotating at Hospital Universitario San Ignacio. Residency programmes have varied lengths from three up to 5 years. In Colombia, medical students have access to residency after completing 6 years of undergraduate training that includes an internship year and a rural service period in which they work as general practitioners paid by the government. Rotations are mostly scheduled in blocks of 2 months. Each residency programme has a fixed number of rotations within its domain but also includes rotations outside its discipline.

\section{Data collection}

We used semi-structured interviews supported by a visual method called the Pictor technique as our primary tool for data collection. The Pictor technique assists participants in exploring and reflecting on their reality and how this reality is constructed by interacting with other people in specific contexts (King et al. 2013). The Pictor technique has been used successfully in medical education research (Berkhout et al. 2017), along with other visual aids-such as drawings-that could help to uncover the complexity of social interactions (Cristancho 2015). The technique consists of using arrow-shaped figures to represent participants' experiences within a social group. The participants are asked to arrange arrow-shaped figures with the names of the people they interact with in a blank page, using the point of the arrows to explain how they interact with these people. These visualisations were then used to guide the interview and as a source for the data analysis (Figs. 1,2).

We selected residents from general surgery and internal medicine using purposive and convenience sampling and invited them to participate in the study. These firsts participants were contacted and invited to participate in the study by CGQ and FOV.

We purposefully sampled a clinical and a surgical discipline from the start to have a broad range of experiences from different medical cultures, including different settings within the workplace. Based on the ongoing data analysis, we shifted to a theoretical sampling of residents from other disciplines including plastic surgery, gynaecology and obstetrics, anaesthesiology, geriatrics and emergency medicine (see Table 1). The most important reason to sample these disciplines was differences in the data analysis between residents rotating within their own disciplines and those rotating in foreign disciplines. FOV gathered contact information from possible participants through recommendations made by the interviewed residents or from his knowledge about rotation schedules of specific programmes. CGQ contacted directly these possible participants and extended the invitation to participate in the study. The interviews were scheduled by FOV or CGQ based on residents' availability; CGQ conducted ten interviews, and FOV conducted three. The interviews were scheduled outside the hospital but within the university campus.

All the interviews were conducted within 2 weeks after a resident started a new rotation to capture the social processes involved in entering a community as a newcomer. 


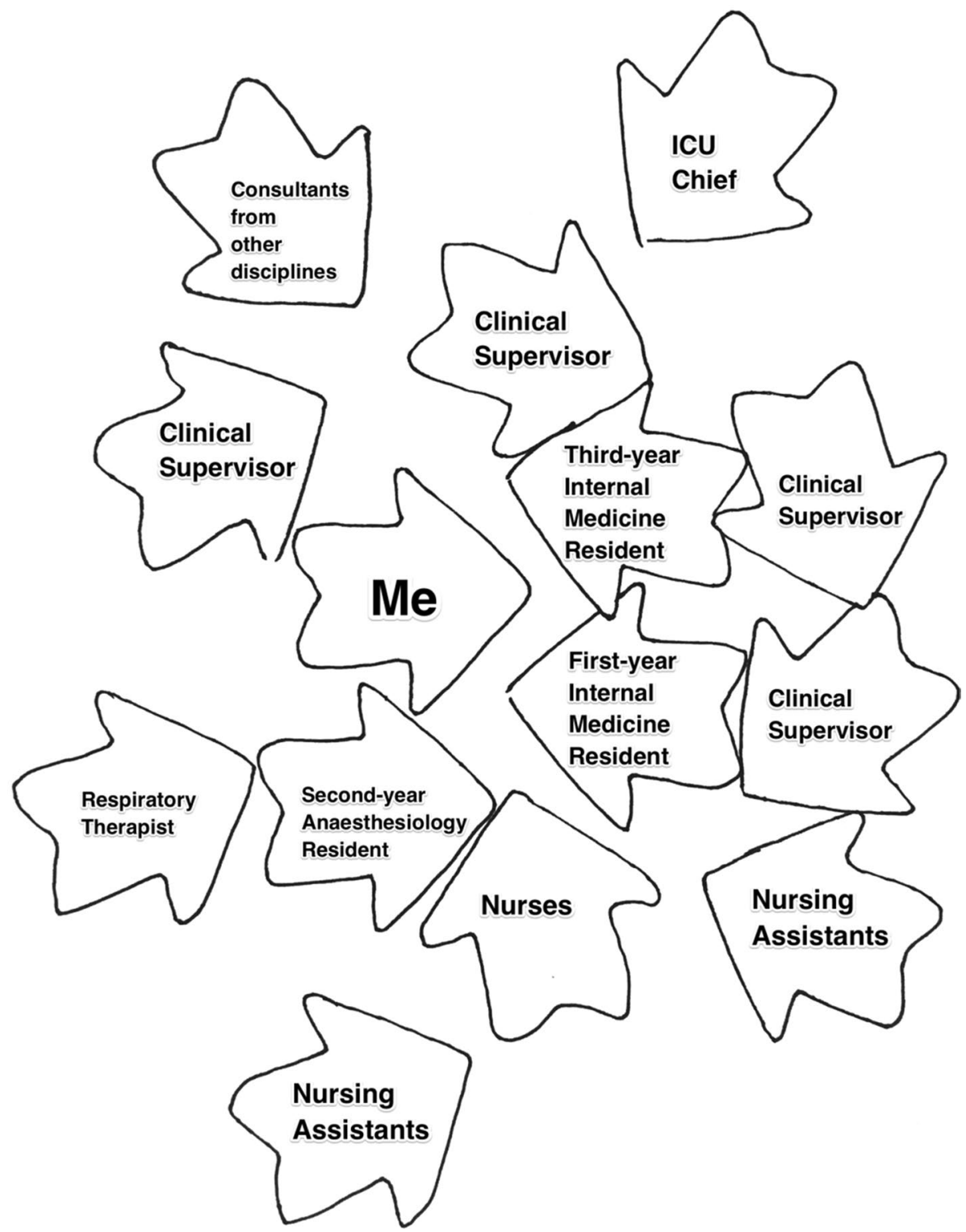

Fig. 1 First-year internal medicine resident beginning his ICU rotation

We designed a questioning route for the interviews (see "Appendix 1") that was informed by the primary goals of the study and that was extensively discussed within the research team. FOV and CGQ worked on a first draft of the route, a draft that was further refined based on DD, RS and PW comments. We performed semi-structured interviews having the questioning route as a guide, but also using probing and follow-up questions to accommodate to theoretical sampling and to trigger participants' reflexivity (Holstein and Gubrium 1995). During the interviews, the residents constructed a Pictor chart that 


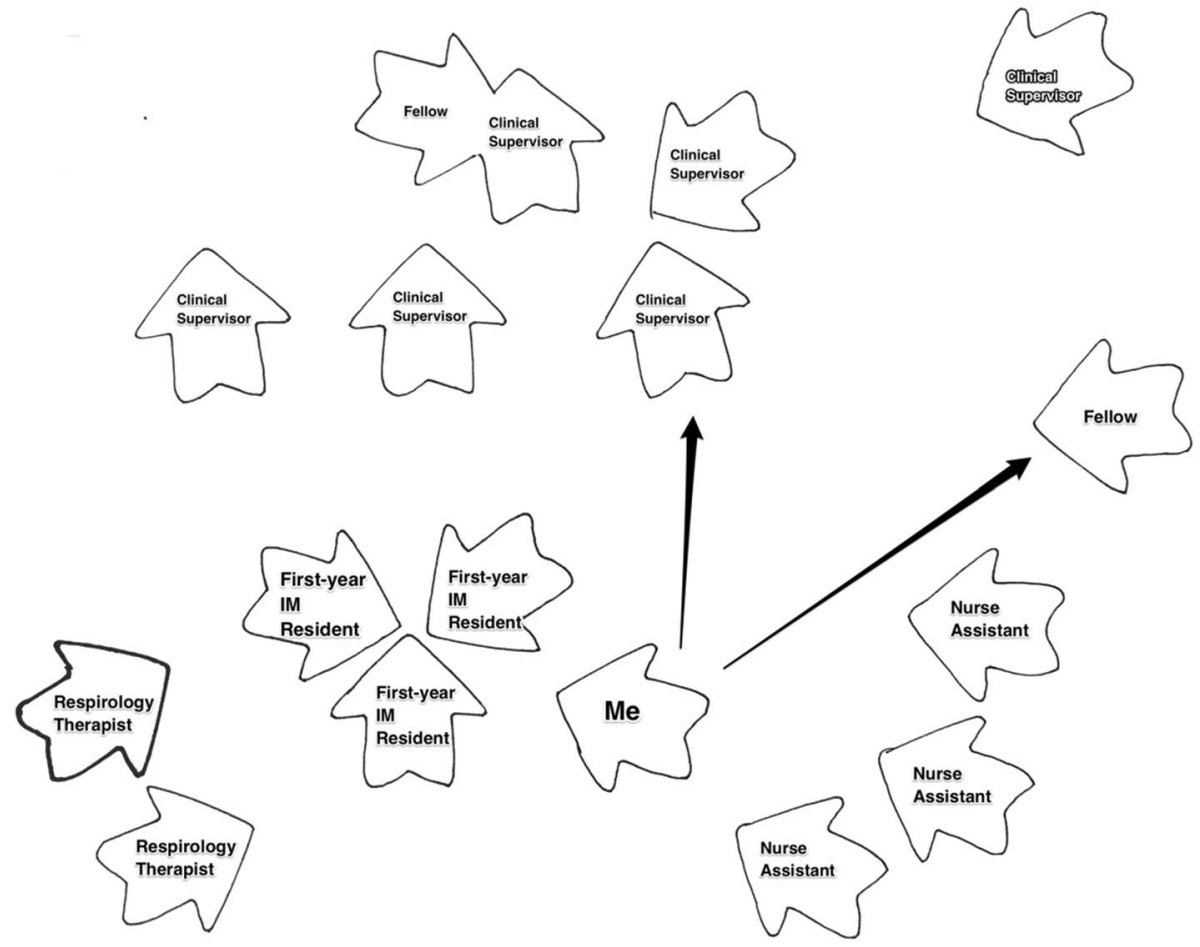

Fig. 2 Second-year anaesthesiology resident beginning her respirology rotation. IM internal medicine

Table 1 Participants' baseline characteristics

\begin{tabular}{llll}
\hline Level of training & Residency programme & Rotation & Gender \\
\hline Junior & Anaesthesiology & Respirology* & $\mathrm{F}$ \\
Junior & Internal medicine & Inpatient ward & $\mathrm{M}$ \\
Junior & Plastic surgery & Head and neck surgery* & $\mathrm{F}$ \\
Junior & Emergency & Anaesthesiology* & $\mathrm{M}$ \\
Junior & Geriatrics & Geriatrics & $\mathrm{M}$ \\
Junior & Internal medicine & Rheumatology & $\mathrm{F}$ \\
Junior & Internal medicine & ICU & $\mathrm{M}$ \\
Junior & Internal medicine & ICU & $\mathrm{F}$ \\
Intermediate & Gynaecology and obstetrics & ICU* & $\mathrm{F}$ \\
Senior & General surgery & Gastrointestinal surgery & $\mathrm{F}$ \\
Senior & General surgery & Thoracic surgery & $\mathrm{F}$ \\
Senior & General surgery & Trauma & $\mathrm{F}$ \\
Senior & Anaesthesiology & Cardiac anaesthesia & $\mathrm{M}$ \\
\hline
\end{tabular}

ICU Intensive care unit; $F$ female; $M$ male

*Residents who were rotating outside their discipline 
reflected their experiences when entering the CoCP, including their interactions with various members of those communities. All the interviews were audiotaped and transcribed verbatim for the data analysis. We scanned all the Pictor charts and anonymised all the personal data, changing names for role titles and identifying residents by their discipline and the rotations they were in at the time of data collection. We used Atlas.Ti v10 for Mac to organise and analyse the transcripts and the charts.

\section{Data analysis}

Constant comparison techniques and iterative data analysis of these pairs of charts/interviews assisted us in constructing an emerging theory (Charmaz 2014). FOV, CGQ and CER open coded the data independently and held meetings to discuss the findings, including conducting focused coding to identify preliminary themes and axial coding to refine and develop the main categories (Charmaz 2014). FOV prepared intermediate reports of these meetings to be discussed with the broader research group including DD, RS and PT. These discussions informed the focus of subsequent interviews and the theoretical sampling of new participants. After thirteen interviews, we reached theoretical sufficiency and stopped data collection. By theoretical sufficiency we mean that our emergent categories were able to explain new collected data without requiring further modifications (Varpio et al. 2017). A summary of the results was sent to all the participants asking them if they agreed with the findings, if their experiences were reflected accurately and if the quotes preserved their meaning after English translation. We received positive comments and no disagreements.

\section{Translation procedures}

All the data, including the transcribed interviews and Pictor charts, are in Spanish. The anonymised Pictor charts were translated into English by FOV. FOV, CGQ and CER coded the raw data in English to share the constructed interpretations with the rest of the team, which also allowed us to adopt an analytical approach to the data and to code more comfortably using the gerund (Helmich et al. 2017). FOV and CER translated the transcripts used in the final draft of the paper. All intermediate drafts used to discuss the findings with the entire team were in English.

\section{Ethics}

The research team obtained permission to conduct the study from the Research Committee of Hospital Universitario San Ignacio and Pontificia Universidad Javeriana. The committee recommended that we avoid any communication that could be taken as coercion by the residents and to be reflexive about including anaesthesiology residents as participants given FOV's position as clinical supervisor of that department. In line with the recommendations, we obtained informed consent from each participant, making it clear that their participation would not affect their assessment or disturb their interactions with the workplace actors. The data were stored so that only the researchers had access to it. We also anonymised all the personal information within the interviews and the Pictor charts. 


\section{Results}

For the residents, entering a new CoCP was characterised by several recurring processes: exploring how their goals and interest are aligned with those of the $\mathrm{CoCP}$; identifying the CoCP members and their roles; and understanding how these members could assist their successful engagement with the community's practices and, therefore, their learning. These three processes were intertwined and influenced each other, which brought complexity to the residents' engagement. To illustrate this complexity, we will present the results by describing two representative fictional stories that capture the essential elements of our analysis. We created these stories based on the primary analysis categories and portray these through fictional situations while anchoring the situations in the data by showing excerpts from various interviews within the narrative. By grounding the fictional stories within the data, we conserve the credibility of our findings, lessening the effects of our interpretations. The names are all fictional, while the quotes are numbered according to the process of participants' anonymisation. We have chosen to present the results in this way because fictional stories are powerful tools that enable readers to resonate with the findings; stories could betoken a shared social experience while triggering in-depth reflection from the part of the readers (Frank 2010).

\section{Story 1: The apprentice}

Carlos is a first-year internal medicine resident in his first weeks of an ICU rotation. This is Carlos' final rotation before being promoted to the second year. Carlos have already rotated through the inpatient ward, the emergency room and some internal medicine departments including respirology and cardiology. He fells ready to tackle the challenges of critically ill patients, and he is excited about the ICU rotation, as he hopes to become an intensivist in the future. During the first days, he works in one of the ICU subunits that have 24 beds for patients with mainly respiratory-related diseases. Unlike the other rotations, the ICU have multiple members from different disciplines who work together clustered in subunits. On the first day of his rotation, Carlos is introduced to his ICU subunit team, which comprise a clinical supervisor, residents from various disciplines, respiratory therapists, nurses and nurse assistants. He rotates with three other residents: a third-year internal medicine resident, a second-year anaesthesiology resident and a third-year emergency medicine resident. The team of residents distributes the patients evenly among themselves; when any of the residents were post-call, the others took over his or her patients. As Carlos put it,

"The work in the ICU is centred on the residents, and we all have the same responsibilities, the same duties; we work together all the time" (R8).

One of Carlos' peers is the internal medicine chief resident, and this is the second time he has rotated in the ICU. The chief resident helps Carlos understand the processes involved in the daily work schedule, including how to deal with the different CoCP members:

"Being in the same group with the chief resident is the best. He knows a lot about how to handle things around here, such as problems with other residents and with nurses, how to tackle difficulties with patients, how to work with each supervisor. Because each person is different; you should know how to talk to them: what to say, how each one liked things to be done" (R12). 
Carlos' job is quite straightforward: he is directly responsible for taking care of his assigned patients; he receives each new patient, assesses his or her condition, establishes a plan and performes daily follow up until the patient could be transferred to the inpatient ward. Carlos describe his role within the community as "central", meaning that without his participation, the workflow would be disrupted. Carlos works with a clinical supervisor who oversees his work while being responsible for teaching tasks:

"The attendings are always with you, that's why I put them like surrounding us [referring to how the resident arranged the arrow-shaped figures in the chart]; we never take a big decision alone, you always talk it through with them, they guide you so you can do your job correctly" (R7).

"Each attending contributes to your professional training. They give you key information that allows you to learn the craft: Conducting rigorous follow up for the patients, doing night shifts, stuff like that. They highlight the importance of working as a learning tool here in your discipline" (R2).

On occasions when the workload is unusually high, the clinical supervisor helps the residents by working side-by-side with them. Experiencing and realising the complexity of critically ill patients, Carlos soon understands how crucial all members of the team are to successfully providing care to this type of patient. For example, he describes the role of nurses in dealing with his new challenges:

"The nurses have a lot of experience. They all have a postgraduate degree in intensive care, so they are experts in what they do. Quite often, mostly in the first days of the rotation, they help you a lot by advising you about how to handle a difficult patient. They also talk you through some practical things, like if they have to administer a drug, then I have to ask them what sort of supplies they need so that I can prescribe the right supplies in the system" (R7).

The role of nurses is dynamic and also include executing what Carlos and the clinical supervisor agree to regarding patient care. Nurses are also crucial to the continuous monitoring of patient changes as they alert Carlos when something is wrong so that he could respond appropriately.

“The nurses! They are your eyes and ears. They monitor the patient up close, so they tell you like 'the blood pressure is low', 'this patient is too sedated' [Referring to the level of patient alertness]. They interact a lot more with the patient than you, so they follow up their progress across the different shifts" (R8).

Carlos also works with a respiratory therapist who teaches him how to programme the ICU ventilators. As with the nurses, the role of the therapist is dynamic and change according to the situation, from teaching Carlos specific skills to carry out his orders to alerting Carlos about patients' respiratory problems.

Carlos make a great effort to establish good relationships with all members of the ICU, as he quickly understands the importance of each person on the team:

"At the end of the day, it is all about how you establish connections with other people and how much of the success in patients' outcomes is determined by the team effort; you know that you haven't achieved all that by yourself. When the patient is in a critical condition, you might focus on a particular aspect, but then someone else comes along and gives you a different perspective, and you see that 
the patient condition improves because of that input. Then you realise that is better to have other people supporting you in this job" (R13).

\section{Story 2: The visitor}

Natalia is beginning her second year as an anaesthesiology resident and she is starting her rotation into the respirology unit. Natalia's goal when entering this rotation is to gain a deeper understanding of the respiratory pathologies she might encounter in patients undergoing surgery while improving her competencies about perioperative assessment and preparation for this type of patient. She feels like a foreigner in a strange land, as the respirology unit is part of the internal medicine department. Natalia rotates with three other residents from the internal medicine programme and a respirology fellow. The existing members of the CoCP include a group of four clinical supervisors, two nurses, four nurse assistants and four respiratory therapists.

Although her goal as an anaesthesiology resident in an internal medicine rotation is clear, her role is not. When asked about how she fells as a member of this team, she says,

"I don't think my role here is indispensable, but I'm of help to them [peers and clinical supervisors]. I assist them with whatever they need" (R4).

During the first weeks, she seems to complete tasks while trying to figure out how to make the best of the rotation. For example, the supervisors assign "easy" patients to her as a way to acknowledge she is not part of the internal medicine programme, while the rest of the residents assume most of the workload. At the same time, some supervisors treats her as if she is an internal medicine resident, demanding that she acquire knowledge that is not of interest to her:

"From my discipline's point of view, some things are not really important for us to learn, but sometimes they [the clinical supervisors] want us to learn things that are not relevant to us. Like learning about lymphomas [a type of cancer that attacks the blood], I do not have to know all the details related to managing patients with lymphoma, but that is what they asked me to know, so I ended up learning it. That knowledge is not really fixed in my mind; I'll forget it in a month" (R9).

Experiencing this tension, she has to quickly determine how to work with the team. She reaches out to the fellow asking for details about how the CoCP worked:

"When I started, I was completely lost, they [the other residents] were already there for almost a month, they knew the place for everything, how the department worked. So, she [the respirology fellow] was the one who explained those things to me. Well, to tell you the truth, she didn't help me, it was more like me asking her, maybe forcing her a little. I had to find out what my job was in this rotation” (R1).

Natalia also enlists the help of one clinical supervisor who seems to have a clearer idea of her goals in this rotation, as she describes in the next excerpt:

"So, I built a good relationship with my clinical supervisor, Dr Gonzalez. He was the one who actually understood my role here; he had a broader picture of the reason for me being here. The rest of the attendings kind of undermined my discipline, but not him. He was like: 'At this point, we should ask for the anaesthetist's opinion; this is what an anaesthetist must know; you as an anaesthetist must learn this" (R1). 
Natalia's interactions with nurses and nurse assistants is also different compared to her anaesthesia rotations. The nurses and nurse assistants do not teach her any specific skills, as she is not interested in learning the procedures of the respiratory unit. Instead, Natalia helps them with whatever task they needed to complete:

"In this rotation, I have a different type of contact with nurses. I help them do their job. Perhaps the clinical supervisor asks them for something, and if I know how to do it, I'll give them a hand: like going to the pharmacy to get a drug or perhaps transferring a patient to a different location" (R4).

As illustrated in the stories, residents' engagement with a $\mathrm{CoCP}$ depended on the alignment between residents' agency (in terms of their goals and interests) and the CoCP expectations and needs regarding the residents' participation within the community. In story 1 , we showed a case of alignment between the resident and the CoCP while in story 2 , we depicted a case where the resident had to negotiate with the CoCP members to come to an alignment between the community needs and the resident' particular goals and interests. For clarity purposes we described an apprentice and a visitor story as examples of alignment and misalignment correspondingly, however, it is important to acknowledge that in the majority of the cases, the CoCPs (as depicted by the residents) seemed to prefer for residents to hold a central role regardless of their personal goals and interests or the type of residency programme they were enrolled in. According to residents' perceptions, this could be due to CoCPs expectations of having a new member that could undertake part of the workload and help the team with completing their tasks. Residents' intention to have a peripheral trajectory within the $\mathrm{CoCP}$, therefore, resulted in a higher degree of misalignment. Concrete examples of alignment in story 1 included how supervisors interacted with Carlos to help him learn from his practice and how his peers aided him in understanding how the CoCP members preferred to work. In story 2, the examples of misalignment included how supervisors demanded that Natalia learned things unrelated to her goals and intentions and how she forced the fellow into helping her to cope with the new CoCP.

The alignment of residents' and CoCP expectations influenced how residents took part in the CoCP practices: a central, aligned participation resulted in a clear role, while a peripheral, misaligned participation tended to result in a vague role, leading to more uncertainties and tensions. In story 1, the alignment between Carlos and the ICU CoCP members regarding Carlos' intention of having a central type of participation, influenced how he engaged with CoCP members to consolidate a team that could contribute to a successful patient outcome. Such alignment also resulted in residents having more dynamic interactions with most of the CoCP members. For example, residents talked about how nurses made suggestions about how to solve patient care problems; they also taught them specific skills while following patient care orders. The opposite situation occurred in story 2: Natalia's intention to have a peripheral position was in direct conflict with the intention of some of the CoCP members, who believed that she should have adopted a central position. She dealt with this lack of alignment by negotiating her role with specific CoCP members in an attempt to remain on the periphery while also being integrated in the CoCP. We also noticed how residents' interactions changed because of these tensions; the interactions seemed to be more limited in terms of their purposes. The most salient case is that of the nurses: In Carlos' story, interactions with nurses had varied and dynamic purposes, while for Natalia interactions were singlepurposed and limited. 


\section{Discussion}

This study set out to explore how residents engage with a CoCP at the start of a new rotation. The residents engaged with a CoCP through complex and interrelated processes that included exploring how their goals and interest are aligned with those of the CoCP; identifying the relevant $\mathrm{CoCP}$ members in the workplace environment; and understanding how these members could assist their successful engagement with the community's practices and, therefore, their learning. Of central importance was how residents' goals and interests when entering a new rotation were aligned with those of the $\mathrm{CoCP}$ members. When aligned, the residents' role was clear and their interactions more dynamic concerning their purposes. When not, residents' role within the CoCP was vague and their interactions with CoCP members were full of tensions.

Much of the workplace learning literature seems to imply that learners have a central role within a community and that they all tend to be interested in a centripetal trajectory within such communities (Balmer et al. 2008; Clement et al. 2016; Strand et al. 2015; Teunissen et al. 2007a, b). According to our findings, residents' trajectories into a CoCP seemed to be more nuanced than that, as some of the residents preferred to remain on the periphery of the community. Communities of practice and landscapes of practice theory recognises different participatory patterns including both inbound trajectories and peripheral trajectories (Wenger 1998; Wenger-Trayner et al. 2014) that are more in line with recent and interprofessional apprenticeship arrangements such as learning in clinical settings (Fuller 2007). Even further, how residents engage with CoCP depends on how those intended trajectories are aligned with the $\mathrm{CoCP}$ expectations and needs regarding the new resident participation within the community. For example, Bannister et al. found that some paediatric residents were not interested in attempting particular clinical skills while rotating in the emergency department because they did not envision themselves as future emergency paediatricians (Bannister et al. 2018). We add to those findings that residents' and $\mathrm{CoCP}$ alignment affects not only how residents engage with members of a $\mathrm{CoCP}$ but also what their final role within that community could be; misalignment, particularly in the case of a peripheral type of participation, could result in resident exclusion from the CoCP or in decreasing learning opportunities. Bunniss and Kelly (2013) also found that healthcare teams exhibited exclusion and inclusion behaviours that determined who was empowered to act upon a patient, positioning their members either in the centre or on the periphery of the community. According to our findings, some residents could also intentionally pursue a peripheral trajectory to learn only partial aspects of that community's knowledge in an effort to hold such trajectory without being excluded from the CoCP.

Based on our findings, workplace learning in postgraduate education results from a balance between residents' agency and CoCPs expectations and needs regarding residents' participation within the community. Residents' agency resulted from their interests and personal goals when entering a new rotation, which was reflected in what type of participatory trajectory they wanted to pursue within the CoCP. Having the intention to pursue a central versus a peripheral trajectory results, as we discovered, in living different social experiences at the beginning of a rotation. This decision triggered different interactions and negotiations with CoCP members, yielding varied learning experiences. This line of reasoning resonates with Billett's co-participation theory, which argues that learning arises from the negotiations between individuals' agency and social affordances (Billett 2002). Teunissen also describes this balance between learners' agency and social learning in his practice-based learning framework: at the end, the learner's trajectory is marked by the 
experiences he or she accumulates throughout his or her training, and each experience is ultimately shaped by the learner's agency (Teunissen 2014). On the other hand, residents' agency alone cannot explain how they participate in the CoCP. As we described, how residents participate in a CoCP resulted from how they negotiated their goals and interests with $\mathrm{CoCP}$ needs and expectations and therefore, how are they are stirred into practice by the CoCP. According to Kemmis' theory of practice, this transformation (the difference between what they intended to vs. what actually happens) is possible because residents are immersed in a practice that holds its own affordances in the form of discourses, spaces and social relationships that go beyond individual interests (Kemmis et al. 2013).

Some practical implications arise from our results. Recognising the variety of residents' roles within a community could help us understand how to maximise the learning potential of workplace settings. Aligning workplace affordances to different residents' trajectories, either central or peripheral, could be the key to decreasing the number of lost learning opportunities. Tackling such a challenge necessarily entails engaging the broader healthcare team in residents' workplace training (Stalmeijer 2015). As we described in our study, nurses, nurse assistants, therapists and physicians from different disciplines have an enormous influence on residents' learning. The more social relationships residents can consolidate, the more they will be accepted and the more learning opportunities they will experience (Bannister et al. 2018). Promoting residents' engagement with the healthcare team might include for them to introduce themselves to all the members, promoting open dialogue about their goals and understanding how each member could assist in their learning agenda. It also includes for residents to be flexible enough to balance their goals with the healthcare team needs.

Our results also imply a challenge to our traditional way of understanding residents' agency in workplace learning. Understanding that residents' role is fluid and influenced by negotiations between the residents and the $\mathrm{CoCP}$ they are entering in is a starting point for new conceptualisations of workplace learning. Future research could explore how to better incorporate residents into a CoCP depending on their participation intention, how they decide what and what not to learn, and whether they have the tools to make these decisions. Additionally, research could explore how we can assist supervisors in ascertaining what roles residents intend to adopt and what specific intentions they have when initiating a new rotation. Clarifying that issue could aid supervisors in more thoroughly promoting residents' exploration of learning goals.

Some limitations should be mentioned. Although we gathered an in-depth picture of the explored process using the Pictor technique, we collected data only from the residents' point of view. We believe this approach answered our research questions; however, it is also essential to examine how community members decide to engage with a resident, how do established members deal with the high rate of resident turnover? To what extent does the community determine the role of the residents and their type of participation? How do such disruptions change the workflow and the continuity of practice itself? Although new conceptualisations of CoP theory consider how learners nurture their trajectories through navigating a landscape of multiple CoPs (Wenger-Trayner and Wenger-Trayner 2014), these frameworks fall short in describing the tensions within these CoPs and how their members address constant changes in their composition. Activity theory (AT) and its subtheory, knotworking, seem to be suitable for answering these queries (Varpio et al. 2008). Both theories have been used to study interprofessional healthcare team collaboration in the past (Bunniss and Kelly 2013; Lingard et al. 2012); however, these frameworks have not been used to explore residents' learning in such teams. Additionally, our theoretical approach also missed the role of spaces and artefacts in residents' engagement with CoCPs. 
Sheehan et al. (2017) have already highlighted the role that material elements (such as the physical space and patient records) play in undergraduate medical training. Actor-network theory (ANT) offers a framework that takes into consideration the contribution of material elements in knowledge construction that could be particularly helpful on exploring such dimension (McMurtry et al. 2016; Latour 2005). Therefore, integrating material elements into workplace learning conceptualisations could open new and uncovered layers of complexity to the ongoing research on this matter, avenues that we were not able to uncover in this study.

\section{Conclusion}

CoCP members' acceptance of residents' participation influences how and what residents learn in clinical settings (Bannister et al. 2018). While exploring how residents enter and engage with a $\mathrm{CoCP}$, we found that this engagement depends on how residents negotiate their intended participation with CoCP members. Based on the residents' agency, residents interact with CoCP members to clarify their role within the new $\mathrm{CoCP}$, a process that is fluent and clear when both parts are aligned but is vague and full of tensions when the parts conflict. Maximising workplace learning entails then to be mindful about the role of the entire healthcare team in residents' engagement on practice, and on understanding the nuances of residents' participatory trajectories while interacting with these members.

Acknowledgements We would like to thank to all the residents that kindly accepted to participate in this study and to Jeannette Suarez for helping us transcribing all the interviews. We also thank to Pontificia Universidad Javeriana, who funded all this study.

\section{Appendix: Questioning route}

\section{Introductory question}

1. Please introduce yourself by telling me your name, which year of residency you are in and what rotation you are starting currently.

\section{Transition questions}

2. What is your job in this rotation? What does it entail?

3. What do you think your role is as part of your work team?

4. How are you experiencing these first weeks in this new rotation?

\section{Directions}

Can you think back to your first week and create a list of people you have interacted with during the beginning of your rotation? Please note their role title within each arrow-shaped sticker. Please be as inclusive as you can. You are free to choose different colours for different actors if you feel that would help you tell your story.

Please place the arrows on this sheet in a way that could help you describe the different relations you have established during this new rotation and their dynamics. You can 
give different directions to the arrows, use different colours, place the arrows at various distances, etc.

\section{Key questions}

5. Please explain this chart to me; why do you portray these relations like this?

a. Why did you choose these colours for these actors?

b. Why did you orient the arrows like this?

6. How do these different actors work together?

7. How did getting to know all these people influence the way you work with them?

8. How did these relations help you find your role or your place in this rotation?

9. It what ways do you think your inclusion on this team has influenced the way the team members work together?

10. How are you adapting to working with these people? How are they adapting to you?

11. Could you tell me about specific situations when you felt you were struggling in that regard?

12. How have you managed that situation?

\section{Wrap-up question}

13. Would you like to add anything to what we have discussed so far?

\section{References}

Balmer, D., Serwint, J., \& Ruzek, S. (2008). Understanding paediatric resident-continuaty preceptor relationships trhough the lens of apprenticeship learning. Medical Education, 42(9), 923-929.

Bannister, S. L., Dolson, M. S., Lingard, L., \& Keegan, D. A. (2018). Not just trust: Factors influencing learners' attempts to perform technical skills on real patients. Medical Education, 52(6), 605-619.

Berkhout, J. J., Helmich, E., Teunissen, P. W., van der Vleuten, C. P., \& Jaarsma, A. D. (2017). How clinical medical students perceive others to influence their self-regulated learning. Medical Education, 51(3), 269-279.

Billett, S. (2002). Workplace pedagogic practices: Co-participation and learning. British Journal of Educational Studies, 50(4), 457-481.

Brown, J., Nestel, D., Clement, T., \& Goldszmidt, M. (2017). The supervisory encounter and the senior GP trainee: managing for, through and with. Medical Education, 52(2), 192-205.

Bunniss, S., \& Kelly, D. R. (2013). Flux, questions, exclusion and compassion: collective learning in secondary care. Medical Education, 47(12), 1197-1208.

Burford, B., Morrow, G., Morrison, J., Baldauf, B., Spencer, J., Johnson, N., et al. (2013). Newly qualified doctors' perceptions of informal learning from nurses: Implications for interprofessional education and practice. Journal of Interprofessional Care, 27(5), 394-400.

Charmaz, K. (2014). Constructing grounded theory. London: SAGE Publications.

Clement, T., Brown, J., Morrison, J., \& Nestel, D. (2016). Ad hoc supervision of general practice registrars as a 'community of practice': Analysis, interpretation and re-presentation. Advances Health Sciences Education, 21(2), 415-437.

Collin, K., Paloniemi, S., \& Mecklin, J. P. (2010). Promoting inter-professional teamwork and learningThe case of a surgical operating theatre. Journal of Education and Work, 23(1), 43-63.

Cristancho, S. (2015). Eye opener: Exploring complexity using rich pictures. Perspectives on Medical Education, 4(3), 138-141. 
Cruess, R. L., Cruess, S. R., \& Steinert, Y. (2018). Medicine as a community of practice: Implications for medical education. Academic Medicine, 93(2), 185-191.

Egan, T., \& Jaye, C. (2009). Communities of clinical practice: The social organization of clinical learning. Health, 13(1), 107-125.

Eraut, M. (2004). Informal learning in the workplace. Studies in Continuing Education, 26(2), 247-273.

Fenton-O'Creevy, M., Brigham, L., Jones, S., \& Smith, A. (2014). Students at the academic workplace boundary: Tourist and sojourners in practice-based education. In E. Wenger-Trayner, M. FentonO'Creevy, S. Hutchinson, C. Kubiak, \& B. Wenger-Trayner (Eds.), Learning in landscapes of practice: Boundaries, identity, and knowledgeability in practice-based learning (pp. 43-63). New York: Routledge.

Frank, A. W. (2010). Letting stories breathe: A socio-narratology. Chicago: University of Chicago Press.

Fuller, A. (2007). Critiquing theories of learning and communities of practice. In J. Huges, N. Jewson, \& L. Unwin (Eds.), Communities of practice: Critical perspectives (pp. 17-28). New York: Routledge.

Gergen, K. (2009). Realities and relationships: Soundings in social construction. Cambridge: Harvard University Press.

Gillespie, B. M., Gwinner, K., Chaboyer, W., \& Fairweather, N. (2013). Team communications in surgery-Creating a culture of safety. Journal of Interprofessional Care, 27(5), 387-393.

Goldman, J., Reeves, S., Wu, R., Silver, I., MacMillan, K., \& Kitto, S. (2015). Medical residents and interprofessional interactions in discharge: An ethnographic exploration of factors that affect negotiation. Journal of General Internal Medicine, 30(10), 1454-1460.

Helmich, E., Cristancho, S., Diachun, L., \& Lingard, L. (2017). 'How would you call this in English? Being reflective about translations in international, cross-cultural qualitative research. Perspectives on Medical Education, 6(2), 127-132.

Holstein, J., \& Gubrium, J. (1995). The active interview. London: Sage publications.

Kemmis, S., Wilkinson, J., Edwards-Groves, C., Hardy, I., Grootenboer, P., \& Bristol, L. (2013). Changing practices, changing education. Singapore: Springer.

King, N., Bravington, A., Brooks, J., Hardy, B., Melvin, J., \& Wilde, D. (2013). The Pictor technique: A method for exploring the experience of collaborative working. Qualitative Health Research, 23(8), $1138-1152$.

Latour, B. (2005). Reassembling the social: An introduction to actor-network-theory. Oxford: Oxford University Press.

Lave, J., \& Wenger, E. (1991). Situated learining: Legitimate peripheral participation. Cambridge: Cambridge University Press.

Lingard, L., McDougall, A., Levstik, M., Chandok, N., Spafford, M. M., \& Schryer, C. (2012). Representing complexity well: A story about teamwork, with implications for how we teach collaboration. Medical Education, 46(9), 869-877.

Lingard, L., Sue-Chue-Lam, C., Tait, G. R., Bates, J., Shadd, J., Schulz, V., et al. (2017). Pulling together and pulling apart: Influences of convergence and divergence on distributed healthcare teams. Advances in Health Sciences Education, 22(5), 1085-1099.

McMurtry, A., Rohse, S., \& Kilgour, K. (2016). Socio-material perspectives on interprofesional team and collaborative learning. Medical Education, 50(2), 169-180.

Noble, C., Brazil, V., Teasdale, T., Forbes, M., \& Billett, S. (2017). Developing junior doctors' prescribing practices through collaborative practice: Sustaining and transforming the practice of communities. Journal of Interprofessional Care, 31(2), 263-272.

Olmos-Vega, F., Dolmans, D., Guzmán-Quintero, C., Stalmeijer, R., \& Teunissen, P. W. (2018). Unravelling residents' and supervisors' workplace interactions: an intersubjectivity study. Accepted for publication at Medical Education.

Olmos-Vega, F. M., Dolmans, D. H. J. M., Vargas-Castro, N., \& Stalmeijer, R. E. (2017). Dealing with the tension: How residents seek autonomy and participation in the workplace. Medical Education, 51, 699-707.

Ong, C. C., Dodds, A., \& Nestel, D. (2016). Beliefs and values about intra-operative teaching and learning: a case study of surgical teachers and trainees. Advances in Health Sciences Education, 21(3), 587-607.

Paradis, E., Leslie, M., \& Gropper, M. A. (2016). Interprofessional rhetoric and operational realities: An ethnographic study of rounds in four intensive care units. Advances in Health Sciences Education, 21(4), 735-748.

Sheehan, D., Jowsey, T., Parwaiz, M., Birch, M., Seaton, P., \& Shaw, S. (2017). Clinical learning environments: Place, artefacts and rhythm. Medical Education, 51(10), 1049-1060.

Stalmeijer, R. (2015). Teaching in the clinical workplace: Looking beyond the power of 'the one'. Perspectives in Medical Education, 4, 103. 
Strand, P., Edgren, G., Borna, P., Lindgren, S., Wichmann-Hansen, G., \& Stalmeijer, R. E. (2015). Conceptions of how a learning or teaching curriculum, workplace culture and agency of individuals shape medical student learning and supervisory practices in the clinical workplace. Advances in Health Sciences Education, 20(2), 531-557.

Swanwick, T. (2005). Informal learning in postgraduate medical education: From cognitivism to 'culturism'. Medical Education, 39(8), 859-865.

Teunissen, P. W. (2014). Experiences, trajectories, and reifications: An emerging framework of practicebased learning in healthcare workplaces. Advances in Health Sciences Education, 20(4), 843-856.

Teunissen, P. W., Boor, K., \& Scherpbier, A. J. J. A. (2007a). Attending doctors' perpectives on how residents learn. Medical Education, 41(11), 1050-1058.

Teunissen, P. W., Scheele, F., Scherpbier, A. J. J. A., Van Der Vleuten, C. P. M., Boor, K., Van Luijk, S. J., et al. (2007b). How residents learn: Qualitative evidence for the pivotal role of clinical activities. Medical Education, 41(8), 763-770.

Varpio, L., Ajjawi, R., Monrouxe, L. V., O’Brien, B. C., \& Rees, C. E. (2017). Shedding the cobra effect: Problematising thematic emergence, triangulation, saturation and member checking. Medical Education, 51(1), 40-50.

Varpio, L., Bidlake, E., Casimiro, L., Hall, P., Kuziemsky, C., Brajtman, S., et al. (2014). Resident experiences of informal education: How often, from whom, about what and how. Medical Education, 48(12), 1220-1234.

Varpio, L., Hall, P., Lingard, L., \& Schryer, C. (2008). Interprofessional communication and medical error: A reframing of research questions and approaches. Academic Medicine, 83(10 Suppl), S76-S81.

Watling, C., \& Lingard, L. A. (2012). Grounded theory in medical education research: AMEE Guide No. 70. Medical Teacher, 34, 850-861.

Wenger, E. (1998). Communities of practice: Learning, meaning and identity. New York: Cambridge University Press.

Wenger-Trayner, E., Fenton-O'Creevy, M., Hutchinson, S., Kubiak, C., \& Wenger-Trayner, B. (2014). Learning in landscapes of practice: Boundaries, identity and knowledgeability in practice-based learning. New York: Routledge.

Wenger-Trayner, E., \& Wenger-Trayner, B. (2014). Learning in a landscape of practice: A framework. In E. Wenger-Trayner, M. Fenton-O'Creevy, S. Hutchinson, C. Kubiak, \& B. Wenger-Trayner (Eds.), Learning in landscapes of practice: Boundaries, identity, and knowledgeability in practice-based learning (pp. 13-29). New York: Routledge.

Publisher's Note Springer Nature remains neutral with regard to jurisdictional claims in published maps and institutional affiliations.

\section{Affiliations}

\section{Francisco M. Olmos-Vega ${ }^{1,2}$ D . Diana H. J. M. Dolmans ${ }^{3}$. Carlos Guzmán-Quintero ${ }^{4}$. Camila Echeverri-Rodriguez $^{1} \cdot$ Pim W. Teunnissen $^{3,5} \cdot$ Renée E. Stalmeijer $^{3}$}

1 Anaesthesiology Department, Faculty of Medicine, Pontificia Universidad Javeriana, Carrera 7 40-62, Fourth Floor, Bogotá, Colombia

2 Hospital Universitario San Ignacio, Bogotá, Colombia

3 School of Health Professions Education, Faculty of Health, Medicine and Life Sciences, Maastricht University, Maastricht, The Netherlands

4 Anthropology Department, Social Sciences Faculty, Pontificia Universidad Javeriana, Bogotá, Colombia

5 VU University Medical Center, Amsterdam, The Netherlands 